\title{
Education and training in optical telecommunications networks in Costa Rica
}

Luis Marin-Naranjo

Luis D. Marin-Naranjo, "Education and training in optical telecommunications networks in Costa Rica," Proc. SPIE 9663, Eighth International Topical Meeting on Education and Training in Optics and Photonics, 96632U (6 October 2003); doi: 10.1117/12.2208497

SPIE Event: Eighth International Topical Meeting on Education and Training in Optics and Photonics, 2003, Tucson, Arizona, United States 


\title{
Education and training in optical telecommunications networks in Costa Rica
}

\author{
Luis D. Marin-Naranjo \\ University of Costa Rica - Photonics and Laser Laboratory LAFTLA - Electrical Engineering School \\ Escuela Ingenieria Electrica UCR, San Jose 2046, Costa Rica \\ telephone: 506207 4700; fax: 506207 4139; e-mail: Imarin@eie.ucr.ac.cr
}

\begin{abstract}
Optical fiber networks began in Costa Rica in 1989 for Telco and Datcom applications. One job at LAFTLA is to give education and training for technical and engineer community that require this technology, including courses at university level. We present how we do that task and what problems we have. (C)2003 Optical Society of America

OCIS codes: (350.4600) Optical engineering; (000.2060) Education
\end{abstract}

\section{Introduction}

Costa Rica is a country in Central America that began installing optical fibers for Telco and Datacom networks since 1989. At University of Costa Rica (UCR) our job in this field began a little bit before in 1986. In 1999 we initiated a program in Photonics and Laser and that result in the Laboratorio de Fotónica y Tecnología Láser (LAFTLA in Spanish). That means Photonics and Laser Technology Laboratory.

Our goals are to work for local industry in areas related to light and optical parameters. As a third world country we do not develop technology but we need to understand and apply standards for day to day jobs trying to get quality. So we prepared a education and training program in applied optics. Because optical fibers communications are important now, we present our experiences in this particular field since 1990.

\section{Physical resources at LAFTLA and country overview}

Our laboratory has now a physical space for academic and practical tasks of $50 \mathrm{~m}^{2}$. Also we are building a new space for calibrating of test equipment following NIST standards as a service for local industry and Laser material processing of another $60 \mathrm{~m}^{2}$. The place is allocated in a satellite campus at University of Costa Rica in San Jose. Our laboratory is about 15 minutes from main campus. The program belongs to Electrical Engineering School as a program developed into the research program of Instituto de Investigaciones en Ingeniería - INNI (Engineering Research Institute of University of Costa Rica).

We get funds from university, self-funding by the courses and services we offer and some donations. Intel for example donated last year two Nd:YAG Lasers for material process each of $30 \mathrm{~W}$.

As any laboratory of this class we do have optical benches and optical tables with breadboards, optomechanical equipment (ThorLabs, Newport, Edmund), optical fiber training equipment (Degen, Newport, Optosci, IFO), Lasers, detectors, optical test equipment (Agilent, Exfo, FIS, Fluke), optical training equipment (Pasco, Newport, Metrologic), optical fiber tool, cables, patch cords, panels, etc. It as been very hard but we consider we have the minimum to work. Our laboratory as air conditioned and environmental control, and we are in process of accreditation in ISO 17025. We work now 2 engineers, two assistants and some temporal professionals from industry. We have good links with Physics Department at UCR but they are not working in applied optics like us.

The main company that uses fiber optics in Costa Rica in telecommunications is ICE (Instituto Costarricense de Electricidad) owner of WAN rings under SDH technology (currently has links at $622 \mathrm{Mbps}$ and $2.5 \mathrm{Gbps}$ ) for Telco and Datacom. ICE has the monopoly of cellular links and subscriber telephony. Also is the company for international links with optical submarine cables. Right now Costa Rica has 2 submarine access, one in the Atlantic Ocean from MAYA and one in the Pacific Ocean from ARCOS. ICE is installing a 32 wavelengths DWDM system around the country and also is testing FSO links in San Jose. Because the irruption in this 5 generation technology appear needs of training in this field. ICE has been training personnel since 1990 but in simple optical fiber systems of second generation. In the next section we expose our experiences to cover this needs.

The whole country has optical fiber cable and Central America will be link via land with optical networks this year. ICE also uses OPGW system along the country for power system control and communications.

Eighth International Topical Meeting on Education and Training in Optics and Photonics,

edited by Barry L. Shoop, Grover Swartzlander Jr., Proc. of SPIE Vol. 9663, 96632U

(c) 2003 SPIE, OSA, ICO · doi: 10.1117/12.2208497 


\section{Optical fiber education and training program at LAFTLA}

At University of Costa Rica I prepared a formal program for Electrical Engineering curricula in Photonics.

It begins with a third year course IE-407 Fields and Waves in Photonics after IE-307 Fields and Waves. This is a B.Sc. course in Electrical Engineering.

For fourth year there is the course IE-0101 Optoelectronics with requisite IE-407. This is also a B.Sc. course in Electrical Engineering or for specialization.

Also for specialization in Telecommunications there is the course IE-0103 Fiber Optics Communications with requisite IE-0101.

In special topics we have also IE-1003 Measurements in fiber optics and IE-1103 Optical Signal Processing and/or Laser Applications (depends of semester).

At Masters level in Digital Communication Program we have two courses in special topics; SP-2110 Optical Networks I and SP-2111 Optical Networks II.

All these courses have laboratory sessions at LAFTLA. We use simulation software from OptiSystem and OptiCad and we use the typical books for example from Palais, Wilson and Hawkes, Saleh and Teich, Agrawal, Hecht/Zajac, Senior, Derickson, etc and the latest review of many sources.

In general education and training in fiber optics we have a program of extensive courses for technicians and engineers. It is for people working now at ICE or in companies giving services to ICE or working with optical fibers.

The courses in order of complexity are:

- Applied optics - theory and practice (30 hours) usually 16 persons. It covers topics and experiments in reflection, refraction, lenses and imaging, diffraction, polarization, laser coherence, interference, light detectors, spectra of light. Experiments in interferometry.

- Course in fiber optics - theory and practice (30 hours) usually 16 persons. It covers topics and experiments in generalities of optical communications, light and optical radiation, types of optical fibers, types of cables, workshops in termination, connectors and splices, patch cords and pigtail, safety handling, basics of measurements with OLS and OTDR, test for installations and maintenance. Standards for records of measurements.

- Course I in DWDM technology- theory and practice (24 hours) usually 16 persons. It covers topics and experiments in fundamentals of optical radiation and light, optical components, optical information codification, DWDM theory and systems. ITU-T standards analysis.

- Course II in DWDM failures and maintenance- theory and practice (24 hours) usually 16 persons. It covers topics and experiments continuing from last course, parameters affecting DWDM signal, failures affecting DWDM signal, management of failures and maintenance in DWDM. Topics on measurements in DWDM.

- Basic course in Metrology in fiber optics- theory and practice (30 hours) usually 16 persons. It covers topics and experiments in statistics, uncertainty calculation, standards, optical measurements, absolute power, optical spectrum, wavelength measurements, calibrating of equipment, PMD measurements, dispersion measurements, DWDM measurements with channel analyzer.

- Course of analysis of optical network- theory and practice (30 hours) usually 16 persons. It covers topics in reflectometry OTDR, components of fibers optics used in line, experiments in single links and WDM links including splices, failures, bending, etc.

\section{Conclusion}

Many private and public companies have sent employees to some of these courses. We have had 140 persons since 1999 and the main topic has been DWDM and measurements. With this interest our job is dynamic and we are contributing to the development of the country. For the companies in Costa Rica the fact to send many people to another country is expensive so we are covering this particular business and generating our own resources to invest in new equipment and improve our location. We are requesting funds from international institutions to get more educational tools. 